\title{
Alternative Methods of Processing of $\alpha$-Methylstyrene: Hydrogenation into Cumene and Isolation as Commercial Product
}

\author{
V. M. Zakoshanskii ${ }^{a}$ and Yu. N. Koshelev ${ }^{b}$ \\ ${ }^{a} 4756$ Doncaster Court, Long Grove, IL 60047-6929, USA \\ phone: (847)913-5861 \\ fax (847)913-5872 \\ e-mail:vlazak@illallc.com,illa.ru@illallc.com,http://www.illallc.com \\ ${ }^{b}$ Illa International, Zheleznodorozhnyi pr. 40, St. Petersburg, 192148 Russia \\ phone: (812)449-43-59, \\ phonelfax: (812)449-43-59 \\ e-mail:koshelev@illallc.com,laboratory@illallc.com \\ Received February 27, 2008
}

This article is withdrawn by the author, must be considered nonexistent and should not be cited. 